\title{
Influence of Composition on Mechanical Properties of Cassava Starch, Sisal Fiber and Carnauba Wax Biocomposites
}

\author{
Áleft Verlanger Rocha Gomes ${ }^{a}{ }_{\mathbb{0}}$, Ricardo Henrique de Lima Leite ${ }^{b}$, Manoel Quirino da Silva \\ Júnior ${ }^{b}$, Francisco Klebson Gomes dos Santos ${ }^{c}$, Edna Maria Mendes Aroucha ${ }^{d}$ \\ ${ }^{a}$ Universidade Federal Rural do Semi-Arido, Mossoró, RN, Brasil \\ ${ }^{b}$ Departamento de Engenharia e Tecnologia, Universidade Federal Rural do Semi-Arido, \\ Mossoró, RN, Brasil \\ 'Departamento de Ciências Naturais, Matemática e Estatística, Universidade Federal Rural do \\ Semi-Árido, Mossoró, RN, Brasil \\ ${ }^{d}$ Departamento de Engenharia e Ciências Ambientais, Universidade Federal Rural do \\ Semi-Árido, Mossoró, RN, Brasil
}

Received: January 20, 2019; Revised: August 26, 2019; Accepted: September 03, 2019

\begin{abstract}
Concern for sustainable development has provided significant improvements in the development of biodegradable materials. This work aims to evaluate, through a central composite design (CCD), the mechanical properties of cassava starch-based biocomposites manufactured with different compositions of carnauba wax (CW), sisal fiber (SF) and glycerol (G). The biocomposites were obtained by casting method. The tensile strength (TS), modulus of elasticity (ME) and elongation at break (El) for the biocomposites were determined by tensile tests. Representative models were obtained to explain changes in mechanical properties of biocomposites as function of composition variables. X-ray diffraction (XRD) and scanning electron microscopy (SEM) were employed to elucidate interactions between the starch matrix and additives A biocomposite with 7.5\% sisal fiber, $10 \%$ carnauba wax and $10 \%$ glycerol showed the best properties to possible applications.
\end{abstract}

Keywords: biodegradable material, composite central design, crystallinity, X-ray diffraction.

\section{Introduction}

The growth of global societies associated with the depletion of natural resources and raise in solid waste production worry the world leaders. Actually, there are an urgent demand to guarantee environmental and material sustainability in the world. However, no effort for sustainability can be successful without causing material producers to consider issues such as greenhouse gas emissions, embedded energy, waste accumulation, and resource depletion. This concern for environmental and material sustainability has led to significant improvements in the development and application of biodegradable materials produced from renewable resources ${ }^{[1,2]}$.

The biopolymers stand out as materials because of their environmentally sustainable characteristics. These materials present biodegradability, low cost, and can be easily obtained from renewable resources. For instance, some biopolymers, like cassava starch ${ }^{[3,4,5]}$, corn starch ${ }^{[6,7]}$ and potato starch ${ }^{[8,9]}$, have been proposed as alternatives to replace non-biodegradable plastic materials. Despite their advantages, biopolymers often have some limiting properties, such as low flexibility, high brittleness and high moisture absorption $^{[10]}$. For this reason, several researches have been carried out to improve the performance of biopolymers. Thus, plasticizers such as glycerol, sorbitol and other polyols are added to biopolymers matrix aiming to rise flexibility and decrease brittleness. Moreover, hydrophobic substances, like waxes, are incorporated to biopolymer matrix in order to lessen moisture absorption ${ }^{[6]}$.

Starch-based biopolymers exhibit poor mechanical properties when compared with synthetic polymeric materials. One way to improves mechanical properties of biopolymers it is to reinforce them with plant fibers, which have low cost, satisfactory mechanical properties and are obtained from renewable sources ${ }^{[1]}$. The materials containing a biopolymer matrix reinforced with plant fibers are known as biocomposites. These can be disposed of without harming the environment and are an alternative to synthetic polymer matrix composites that are hazardous, biorecalcitrants and have an aggressive effect on human health ${ }^{[2,12]}$.

The high moisture absorption ability presented by biocomposites with starch-based matrix affects the properties of these materials, in particular their mechanical properties, as well as its life cycle ${ }^{[3]}$. Hydrophobic materials, such as waxes, may be added to starch matrix in order to reduce the moisture absorption. However, a high waxes content provokes a negative effect on mechanical properties of biocomposites ${ }^{[13,14]}$. 
In the present study, a central composite design (CCD), which is a widely used form of response surface methodology (RSM), was employed to evaluate the influence of additives contents on the mechanical properties of cassava (Manihot esculenta) starch-based biocomposites. The factors (independent variables) investigated were the contents in glycerol, carnauba (Copernicia prunifera) wax and sisal (Agave sisalana) fibers utilized to make the biocomposites. The response variables studied were tensile strength (TS), modulus of elasticity (ME) and elongation at break (E1). In addition, X-ray diffraction (XRD) and scanning electron microscopy (SEM) were employed to elucidate interactions between the starch matrix and additives.

\section{Experimental}

\subsection{Materials}

Cassava starch and glycerol were purchased from Primícias do Brasil, Co., Brazil and Dinâmica Química Contemporânea Co., Brazil, respectively. Carnauba wax type I and sisal fibers were kindly donated by Agrocera Co., Brazil and Sisaltec Co., Brazil, respectively.

\subsection{Methods}

\subsubsection{Experimental design and statistical analysis}

Central composite design (CCD), also known as BoxWilson design, is an experimental design that allows maximize the quantity of information obtained from a minimal set of essays. The CCD incorporate a factorial design which is augmented with center points and a group of axial points ('star points') that allow estimation of model curvature. The axial points are placed at some distance ' $\alpha$ ' from center point of the design. The central composite face-centered (CCFC) is a variety of CCD design, in which the star points are at the center of each face of the factorial space, so $\alpha= \pm 1$.

In this work, a CCFC experimental design was used to determine the influence of three compositions variables (glycerol, carnauba wax and sisal fibers contents) on mechanical properties of cassava starch-based biocomposites. The factors ranges were determined from preliminary experimental essays. For instance, values for the factors outside the selected ranges produced too brittle materials to perform the tensile tests. After selection of independent variables and their ranges, experiments were established based on a CCFC design with three factors at three levels coded as 1 , 0 and +1 . The real and coded values for the independent variables (factors) are listed in Table 1.

Biocomposites containing only cassava starch, without plasticizer ( $0 \%$ glycerol), were too brittle and mechanically unstable, not allowing the tests to be performed. So, they were not considered in experimental planning (Table 1).

A total number of 17 essays consisting of 8 factorial points, six axial points and three replicates at the center point (in order to allow the estimation of pure error) were carried out. Homoscedasticity was assumed for responses in whole experimental domain. The experimental sequence was randomized in order to minimize the effects in the responses due to spurious factors. A second-order polynomial equation was used in order to develop an empirical model which correlated the responses to the independent variables. The general form for second order polynomial model is presented in Eq. (1).

$$
\begin{aligned}
& Y_{i}=b_{0}+b_{1} X_{1}+b_{2} X_{2}+ \\
& b_{11} X_{1}^{2}+b_{22} X_{2}^{2}+b_{33} X_{3}^{2}+ \\
& b_{12} X_{1} X_{2}+b_{13} X_{1} X_{3}+ \\
& b_{23} X_{2} X_{36}+\varepsilon_{i}(i=1,2 \text { or } 3)
\end{aligned}
$$

Here, $Y_{i}$ represents dependent variables, where $Y_{l}$ is the tensile strength in $\mathrm{MPa}, Y_{2}$ is the modulus of elasticity in $\mathrm{MPa}$, and $Y_{3}$ is the elongation at break in percentage; $X_{1}, X_{2}$ and $X_{3}$ are the independent variables, sisal fibers (SF), carnauba

\begin{tabular}{|c|c|c|c|c|c|}
\hline \multicolumn{3}{|c|}{ Independent variables (factors) } & \multicolumn{3}{|c|}{ Ranges and levels } \\
\hline Variable names and abbreviations & Units & Coded names & Levels & Coded values & Real values \\
\hline \multirow{3}{*}{ Sisal fibers content (SF) } & \multirow{3}{*}{$\%$} & \multirow{3}{*}{$\mathrm{X}_{1}$} & Low & -1 & 0 \\
\hline & & & Medium & 0 & 7.5 \\
\hline & & & High & +1 & 15 \\
\hline \multirow{3}{*}{ Carnauba wax content $(\mathrm{CW})$} & \multirow{3}{*}{$\%$} & \multirow{3}{*}{$\mathrm{X}_{2}$} & Low & -1 & 0 \\
\hline & & & Medium & 0 & 15 \\
\hline & & & High & +1 & 30 \\
\hline \multirow{3}{*}{ Glycerol content $(\mathrm{G})$} & \multirow{3}{*}{$\%$} & \multirow{3}{*}{$X_{3}$} & Low & -1 & 10 \\
\hline & & & Medium & 0 & 20 \\
\hline & & & High & +1 & 30 \\
\hline
\end{tabular}
wax $(\mathrm{CW})$ and glycerol $(\mathrm{G})$ contents, respectively, expressed in percentage; $\mathrm{b}_{0}$ is the intercept; $b_{1}, b_{2}$ and $b_{3}$ are the linear

Table 1. Experimental ranges and levels of the independent test variables. 
coefficients; $b_{11}, b_{22}$ and $b_{33}$ are quadratic coefficients; $b_{12}, b_{13}$ and $b_{23}$ are the interactives coefficients; and $\varepsilon_{i}$ is the error.

$A$ variance analysis (ANOVA) and $\mathrm{F}$ test were performed to verify if the models were statistically significant at $\mathrm{p}<$ 0.05 . For the models in which the $\mathrm{F}_{\text {calculated }}$ was superior to the $F_{\text {critical }}$ and $R^{2} \geq 0.75$, the response surfaces were represented as three-dimensional contour plots. During the adjustment of the models, non-significant effects were ignored. All Statistical analysis of data obtained through the experimental design was performed, using the software Statistica ${ }^{\circledR}$ version 13.5 (TIBCO softtware Inc., USA).

\subsubsection{Preparation of biocomposites}

Initially, precursor mixtures were obtained with a mass of total dry matter fixed at $20 \%(\mathrm{w} / \mathrm{w})$ using osmosed water as solvent. Dry matter mass is the sum of cassava starch, sisal fibers, carnauba wax and glycerol masses. The masses of sisal fibers, carnauba wax and glycerol ranged in accord with contents set in the experimental design for each run. The mass of cassava starch was calculated by difference between the mass of dry matter total and the masses of fibers, wax and plasticizer used in each experiment. Before the preparation, the sisal fibers were cut and its lengths uniformized at $20 \mathrm{~mm}$. The first step in preparation of the precursor mixture was the dispersion in water of the cassava starch, glycerol and sisal fibers, according the calculated amounts for each run. This mixture was heated and the temperature kept constant at approximately $90^{\circ} \mathrm{C}$, under constant mechanical stirring until complete starch gelatinization. A change in mixture aspect from opaque to translucid indicates the complete starch gelatinization, which occurs in about 30 minutes of heating. The carnauba wax was added after starch gelatinization and under enough stirring to ensure mixture homogeneity. The temperature and stirring conditions required in experiments were achieved by a mechanical homogenizer (TE-099, Tecnal) and a thermostatic bath. Once prepared, precursor mixtures were deposed in trays $(20 \mathrm{~cm} \times 30 \mathrm{~cm})$ and dried in oven with air renovation (TE-394/1, Tecnal) at $60^{\circ} \mathrm{C}$ during 60 hours.

\subsubsection{Mechanical Testing}

Tensile strength (TS), modulus of elasticity (ME) and elongation at break (El) were determined according to ASTM D3039 ${ }^{[15]}$, under ambient conditions, using an EMIC DL10000 Universal Testing Machine (Emic Equipamentos e Sistemas de Ensaios LTDA, São José dos Pinhais, Brazil). Prior to testing, samples were equilibrated at $75 \%$ relative humidity in a sealed chamber containing saturated solutions of sodium chloride ${ }^{[16]}$. The testing conditions used were: load cell of $5 \mathrm{kN}$ and cross head speed of $5 \mathrm{~mm} / \mathrm{min}$. At least five test specimens were tested with dimensions of $100 \mathrm{~mm} \times 20 \mathrm{~mm}$. The thickness for each test specimen was measured at five random points using an EDA analog micrometer with 0.01 $\mathrm{mm}$ resolution. A mean thickness was calculated and used to determine the mechanical properties of the biocomposites.

\subsubsection{Scanning Electron Microscopy (SEM)}

For each biocomposite, fracture surfaces morphology was analyzed using a scanning electron microscope (SEM), model Tescan VEGA 3, operating at a voltage of $10 \mathrm{kV}$. Before analysis, samples were fixed in a metal support with carbon tape and then metallized with a thin layer of gold to make them conductive. The images were obtained by secondary electrons (SE), with magnifications of 500x. The working distances were fixed about $15 \mathrm{~mm}$ for all micrographs, except in the case of biocomposite XV, for which was achieved a sharper image at working distance of approximately $29 \mathrm{~mm}$.

\subsubsection{X-ray diffraction $(X R D)$}

The biocomposites crystallinity was determined by $\mathrm{X}$-ray diffraction (XRD). The XRD analysis were carried out using a Shimadzu diffractometer, model XRC-6000, with monochromatic $\mathrm{CuK} \alpha$ radiation $(\lambda=1.5418 \AA)$ and operating conditions of $40 \mathrm{keV}$ and $30 \mathrm{~mA}$. The $2 \theta$ angle ranged between 10 and $60^{\circ}$ with a scanning speed of $2^{\circ} \%$ $\mathrm{min}$. The amorphous and crystalline areas in diffractograms were obtained by deconvolution calculus using OriginPro 8 program. The relative crystallinity of the biocomposites was calculated according to Eq. (2).

$$
R C-\frac{A C}{A C+A A}
$$

Where, $\mathrm{RC}$ is the relative crystallinity, $\mathrm{AC}$ is the crystalline area and $\mathrm{AA}$ is the amorphous area in biocomposites diffractograms.

\section{Results and Discussion}

Figure 1 presents selected SEM images of the fractured surfaces for some materials prepared in this study. The Figure 1(a) shows the fracture surface for a cassava starch matrix with low glycerol content $(10 \%)$, which can be compared with the fracture image, presented in Figure 1(e), for a similar matrix with high glycerol content (30\%). The biopolymer with low glycerol content exhibits a surface with cracks characteristic of a fragile fracture while a cracks free surface, indicating a ductile fracture, is observed for the similar material with high glycerol content. This demonstrate the increasing in material flexibility provoked by the glycerol plasticizing effect. Actually, glycerol molecules can stablish hydrogen bond between adjacent polymeric chains in starch matrix, allowing them glide easily under mechanical effort, what increases macromolecules mobility and reduces material fragility $[3,17,18]$.

Figure 1(b) shows a fractured surface for a cassava starch-based biocomposite containing $15 \%$ sisal fiber and 


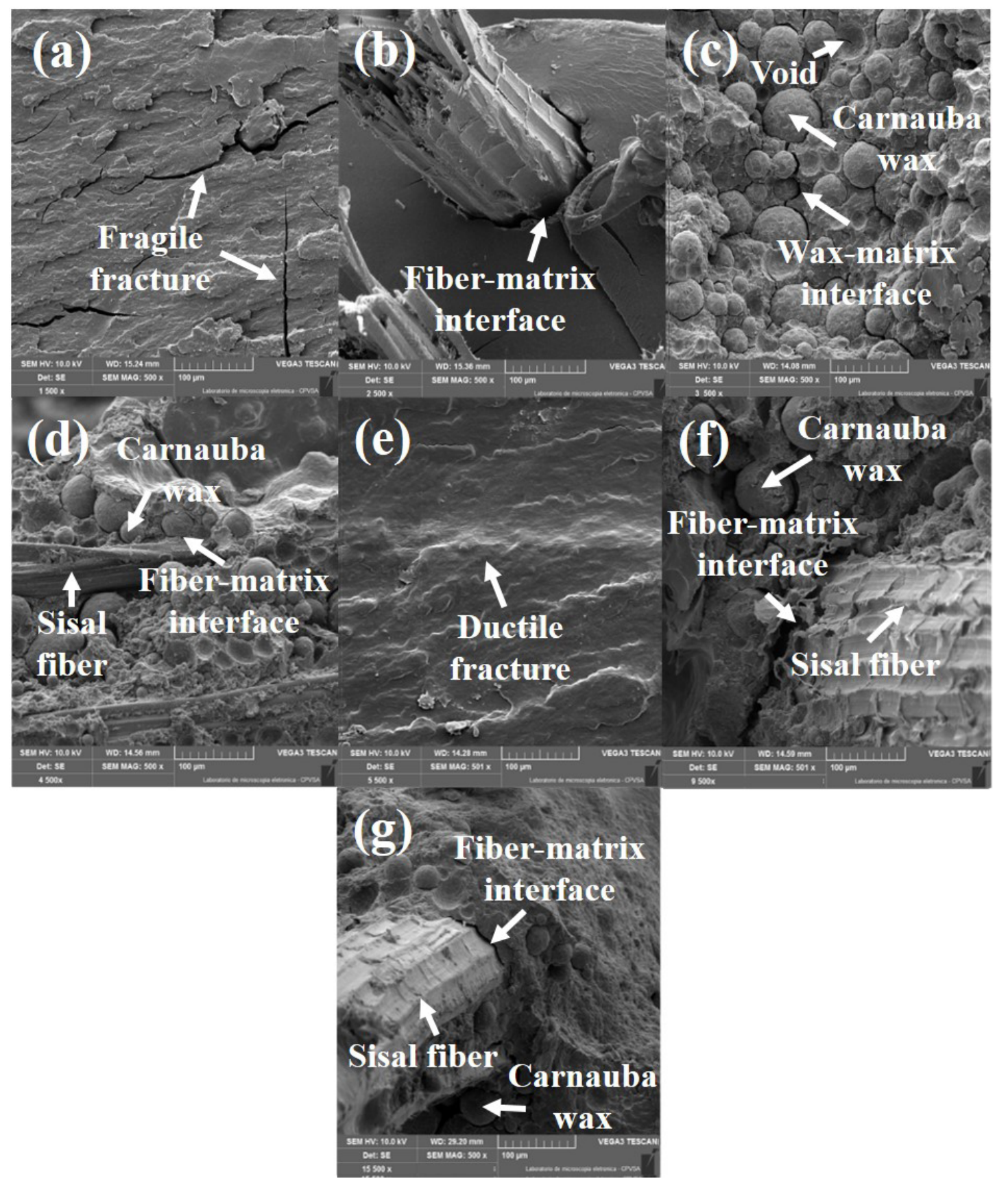

Figure 1. Scanning electron micrographs of the fractured surfaces for the biocomposites (a) I, (b) II, (c) III, (d) IV, (e) V, (f) IX and (g) XV.

$10 \%$ glycerol. A good anchorage between the fibers and the matrix can be observed. In fact, the image reveals the fibers attached to the starch matrix even after breaking the material under tensile stress. This demonstrates a good interfacial adhesion, possibly due to the interaction through hydrogen bonds between surface hydroxyl groups present in the sisal fibers and starch matrix. Furthermore, since anchorage is responsible for transferring the matrix tension to the fibers, it is expected that a good interfacial adhesion improves the mechanical properties of the biocomposites ${ }^{[3]}$.

Figure 1(c) shows the fracture surface of a cassava starch-based biocomposite containing $\mathrm{G}(10 \%)$ and $\mathrm{CW}$ $(20 \%)$. It is possible to observe a poor interfacial adhesion of starch hydrophilic matrix with the $\mathrm{CW}$ hydrophobic particles. A high CW content leads to the formation of voids and agglomerates of this component, due to its inability to 
mix with the matrix. Such behavior was also observed by Mehyar et al. ${ }^{[19]}$ and results in structural defects in the matrix which reduces the mechanical strength and flexibility of the biocomposites by formation of stress concentrators.

The Figure 1(d) shows fracture surfaces for the biocomposite manufactured with the highest SF and CW contents (15\% and $20 \%$, respectively) employed in this study, but with a low $\mathrm{G}$ content $(10 \%)$. It can be observed $\mathrm{CW}$ particles distributed in the starch matrix, as well as, at interface fiber-matrix. The $\mathrm{CW}$ particles can reduce the fiber-matrix interfacial adhesion and can compromise the mechanical properties for biocomposites ${ }^{[20]}$. Furthemore, mechanical properties for that biocomposites can also be impaired because there are SF agglomerations and an amount of starch matrix insufficient to coat all fibers, which was also observed by Ibrahim et al. ${ }^{[21]}$.

Figure 1(f) presents fracture surfaces for biocomposites fabricated with intermediate $\mathrm{SF}$ and $\mathrm{CW}$ contents $(7,5 \%$ and $10 \%$, respectively) and low G content (10\%). Figure 1(g) shows a biocomposite with the same SF and CW contents, but with higher G content (20\%) than former one. Comparing these SEM images, it is visible that a rise in $\mathrm{G}$ content enables starch matrix to better enfold CW particles and sisal fibers. This is likely occasioned by the increased flexibility of starch matrix with high $\mathrm{G}$ content, which reduces cracks at interfaces.

The XRD results for some selected biocomposites can be observed in Figure 2. The diffractograms for the biocomposites containing SF (II, IV, IX and XV) show a main diffraction peak $2 \theta$ at $22.4^{\circ}$, corresponding to the crystallographic plane (200) and associated with the cellulose present in sisal fibers. This peak is not observed in diffractograms for biocomposites without SF (I and V). The diffractogram for the biocomposite III, which contains $\mathrm{CW}$, exhibits two main diffraction peaks $2 \theta$ at $21.6^{\circ}$ and $23.8^{\circ}$. These peaks were also observed by Villalobos-Hernandez and Muller-Goymann ${ }^{[22]}$.

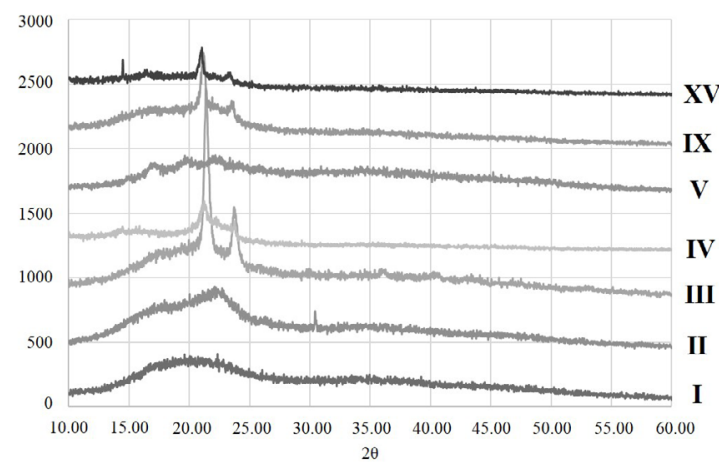

Figure 2. X-ray diffractograms for some selected biocomposites.

Table 2 summarizes the relative crystallinities (RC) calculated from the diffractograms of the selected biocomposites as shown in Figure 2. An increase in SF content increases the crystallinity of the material as well as the addition of CW. This is due to cellulose present in lignocellulosic fibers, such as FS, and has also been observed in other studies ${ }^{[4,23]}$. On the other hand, an increase in $\mathrm{G}$ content reduces the crystallinity for the biocomposites. This is understandable, since the glycerol molecules remain between polymer chains and difficult the formation of ordered structures (crystallites) in the starch matrix ${ }^{[20]}$.

Table 2. Relative crystallinity (RC) for selected biocomposites

\begin{tabular}{lcccc}
\hline $\begin{array}{l}\text { Biocomposite } \\
\text { (Run) }\end{array}$ & \multicolumn{3}{c}{ Composition (\%) } & RC (\%) \\
\hline I & SF & CW & G & \\
II & 0 & 0 & 10 & 39.1 \\
III & 15 & 0 & 10 & 45.5 \\
IV & 0 & 20 & 10 & 46.5 \\
V & 15 & 20 & 10 & 56.4 \\
IX & 0 & 0 & 30 & 24.6 \\
XV & 7.5 & 10 & 10 & 51.7 \\
\hline
\end{tabular}

According to Ramírez et al. ${ }^{[4]}$ there is a correlation between relative crystallinity and mechanical properties. The rising in relative crystallinity increases the tensile strength and modulus of elasticity, as well as decreases the elongation at break. This behavior was also observed in the present work.

Table 3 shows the mean values of the dependent variables evaluated: tensile strength (TS), modulus of elasticity (ME) and elongation at break (El) for the biocomposites with the different compositions studied.

The highest value obtained for TS was $11.22 \mathrm{MPa}$, relative to the biocomposite (II) containing $15 \% \mathrm{SF}$ and $10 \% \mathrm{G}$ (without $\mathrm{CW}$ ), while the lowest value was 0.62 MPa for the biocomposite (VII) with $20 \% \mathrm{CW}$ and $30 \% \mathrm{G}$ (without SF). The SF has a high resistance that is rightly transfer to biocomposite ${ }^{[3,23]}$. This transfer is assured by a good anchorage between SF and cassava starch matrix, as was shown in SEM images. The lowest TS value for the biocomposite with the highest $\mathrm{CW}$ and $\mathrm{G}$ contents is possibly due to poor interaction between the $\mathrm{CW}$ and starch matrix, as well as to plasticizing effect of $G$ that leaves the matrix less resistant ${ }^{[6,20]}$.

The ME measures the level of stiffness for a material. Regarding the ME, the highest value (235.6 MPa) was obtained for the biocomposite (II) with $15 \%$ SF and $10 \% \mathrm{G}$, while the lowest value was 4.2 MPa for the biocomposite (V) with $30 \%$ glycerol (without SF and CW). Thus, the rigidity of the biocomposites increases with the content of SF. Again, this is only possible because there is a good anchorage of the reinforcement (SF) in the matrix. Probably, this behavior originates from the combined effect of the fibers stabilizing the starch matrix and distributing the stress throughout the material. Thus, a higher tension is required to deform the 
Table 3. Mean values and standard deviation of the tensile strength (TS), modulus of elasticity (ME) and elongation at Break (El) for biocomposites.

\begin{tabular}{|c|c|c|c|c|c|c|}
\hline \multirow{2}{*}{ Biocomposite (Run) } & \multicolumn{3}{|c|}{ Composition $(\%)^{*}$} & \multicolumn{3}{|c|}{ Mechanical properties } \\
\hline & $\mathrm{SF}\left(\mathrm{X}_{1}\right)$ & $\mathrm{CW}\left(\mathrm{X}_{2}\right)$ & $\mathrm{G}\left(\mathrm{X}_{3}\right)$ & $\mathrm{TS}\left(\mathrm{Y}_{1}\right)$ & $\operatorname{ME}\left(\mathrm{Y}_{2}\right)$ & $\mathrm{El}\left(\mathrm{Y}_{3}\right)$ \\
\hline I & $0(-1)$ & $0(-1)$ & $10(-1)$ & $3.74 \pm 1.04$ & $92.6 \pm 32.5$ & $22.77 \pm 6.46$ \\
\hline II & $15(+1)$ & $0(-1)$ & $10(-1)$ & $11.22 \pm 2.39$ & $235.6 \pm 76.3$ & $6.72 \pm 0.47$ \\
\hline III & $0(-1)$ & $20(+1)$ & $10(-1)$ & $2.62 \pm 0.20$ & $98.3 \pm 21.01$ & $3.78 \pm 0.59$ \\
\hline IV & $15(+1)$ & $20(+1)$ & $10(-1)$ & $4.92 \pm 1.45$ & $120.0 \pm 27.4$ & $5.26 \pm 0.89$ \\
\hline $\mathrm{V}$ & $0(-1)$ & $0(-1)$ & $30(+1)$ & $0.86 \pm 0.11$ & $4.2 \pm 0.1$ & $16.13 \pm 3.91$ \\
\hline VI & $15(+1)$ & $0(-1)$ & $30(+1)$ & $2.14 \pm 0.43$ & $55.6 \pm 12.9$ & $5.26 \pm 0.68$ \\
\hline VII & $0(-1)$ & $20(+1)$ & $30(+1)$ & $0.62 \pm 0.05$ & $8.1 \pm 0.5$ & $6.70 \pm 0.83$ \\
\hline VIII & $15(+1)$ & $20(+1)$ & $30(+1)$ & $1.10 \pm 0.12$ & $40.7 \pm 4.5$ & $2.97 \pm 0.24$ \\
\hline IX & $7.5(0)$ & $10(0)$ & $10(-1)$ & $6.56 \pm 0.44$ & $169.0 \pm 26.7$ & $5.21 \pm 0.49$ \\
\hline $\mathrm{X}$ & $7.5(0)$ & $10(0)$ & $30(+1)$ & $1.37 \pm 0.22$ & $43.8 \pm 7.3$ & $4.02 \pm 0.47$ \\
\hline XI & $7.5(0)$ & $0(-1)$ & $20(0)$ & $4.02 \pm 0.56$ & $85.3 \pm 14.3$ & $7.10 \pm 1.28$ \\
\hline XII & $7.5(0)$ & $20(+1)$ & $20(0)$ & $2.60 \pm 0.58$ & $76.9 \pm 19.1$ & $3.93 \pm 0.53$ \\
\hline XIII & $0(-1)$ & $10(0)$ & $20(0)$ & $0.88 \pm 0.20$ & $11.6 \pm 2.5$ & $5.12 \pm 2.21$ \\
\hline XIV & $15(+1)$ & $10(0)$ & $20(0)$ & $3.57 \pm 0.89$ & $82.0 \pm 20.6$ & $5.84 \pm 0.60$ \\
\hline$X V$ & $7.5(0)$ & $10(0)$ & $20(0)$ & $2.83 \pm 0.89$ & $71.8 \pm 21.9$ & $5.30 \pm 0.89$ \\
\hline XVI & $7.5(0)$ & $10(0)$ & $20(0)$ & $3.94 \pm 0.78$ & $91.3 \pm 11.1$ & $6.32 \pm 1.11$ \\
\hline XVII & $7.5(0)$ & $10(0)$ & $20(0)$ & $3.95 \pm 1.21$ & $98.1 \pm 25.7$ & $5.53 \pm 0.92$ \\
\hline
\end{tabular}

$(*)$ coded values for independent variables are presented in parenthesis. TS and ME are expressed in MPa. El is expressed in \% of elongation.

biocomposite. Unlike, a rising in $\mathrm{G}$ content reduces the $\mathrm{ME}$ because glycerol molecules provoke a gliding effect between polymeric chains of the starch matrix. So, a lower tension is necessary to deform the material.

Elongation at break had a maximum value of $22.77 \%$ for the biocomposite (I) with 10\% glycerol (without SF and $\mathrm{CW}$ ), while the lowest value was $2.97 \%$ for the biocomposite (VIII) with $15 \% \mathrm{SF}, 20 \% \mathrm{CW}$ and $30 \% \mathrm{G}$. The results indicate a decrease in the ability of the material to undergo deformation without breaking when the content of additives increases ${ }^{[6,20]}$.

The coded models proposed to describe the tensile strength $\left(\mathrm{Y}_{1}\right)$, the modulus of elasticity $\left(\mathrm{Y}_{2}\right)$ and elongation at rupture $\left(\mathrm{Y}_{3}\right)$ of the studied biocomposites within the experimental domain are described in Table 4. Only statistically significant terms were considered in final models. In order to obtain a model with the subset of terms that maximizes $\mathrm{R}_{\text {adjusted }}$ value, some regression coefficients were disregarded. In all cases the $\mathrm{R}^{2}$ value was higher than 0.85 and the $\mathrm{F}_{\text {calculated }}>\mathrm{F}_{\text {critical }}$ for a confidence level of $95 \%$, indicating that the models were significant. The values of $\mathrm{R}^{2}, \mathrm{R}_{\text {adjusted }}, \mathrm{F}_{\text {calculated }}$ and $\mathrm{F}_{\text {critical }}$ for the models are also presented in Table 4.

Response surface (RS) graphs were plotted (Figure 3) from the models fitted to the experimental data. These show the influence of the composition of the biocomposites on their mechanical properties. Each RS shows the variation of a mechanical property, (TS, ME or El) as a function of two composition variables ( $\mathrm{SF}, \mathrm{CW}$ or $\mathrm{G}$ ), while a third composition variable is kept constant.

Regarding TS and ME, there is an increase in these properties with the incorporation of sisal fiber throughout the studied domain ( 0 to $15 \% \mathrm{SF}$ ), as shown in Figure 3(a) and (d). This is indicated by the positive linear parameter in model. Possibly, such behavior is associated with the rising in crystallinity of the biocomposite observed in XRD results. Similar effect was reported by Ramírez et al. ${ }^{[4]}$ and Zainuddin et al. ${ }^{[23]}$. Also, the increase in TS and ME, with the incorporation of SF, is related to the strong interaction of the fibers with the cassava starch matrix. Sisal fibers and starch matrix interact forming hydrogen bonds through their surface hydroxyl groups. This interaction leading to a good stress transfer between the matrix and reinforcement in material ${ }^{[3,23,24]}$.

On the other hand, the models predict a maximum in TS and ME at higher concentrations of sisal fiber, which is indicated by a negative quadratic parameter associated with the variable SF. According to the model obtained and considering the minimum concentrations of carnauba wax $(0 \%)$ and glycerol (10\%), it is observed that the maximum values of TS and ME would be obtained with the concentrations of $20.72 \%$ and $31.94 \%$ of sisal fiber, respectively. Some authors report that a excessive fiber contents can cause a bad dispersion of the reinforcement, the formation of fiber 
Table 4. Prediction of mechanical properties for the biocomposites by fitting models with the obtained data.

\begin{tabular}{|c|c|c|c|c|}
\hline The best fitted models* & $\mathrm{R}^{2}$ & $\mathrm{R}_{\text {adjusted }}$ & $\mathrm{F}_{\text {calculated }}$ & $\mathrm{F}_{\text {critical }}$ \\
\hline $\begin{array}{l}Y_{1}=8.882+0.793 \cdot X_{1}-0.180 \cdot X_{2}-0.550 \cdot X_{3}-0.016 \cdot X_{1}^{2}+0.009 \cdot X_{3}^{2}-0.010 \cdot X_{1} \cdot X_{2}- \\
0.013 \cdot X_{1} \cdot X_{3}+0.008 \cdot X_{2} \cdot X_{3}\end{array}$ & 0.962 & 0.923 & 25.5 & 2.59 \\
\hline$Y_{2}=247.634+17.503 \cdot X_{1}-17.371 \cdot X_{3}-0.548 \cdot X_{1}^{2}+0.288 \cdot X_{3}^{2}-0.234 \cdot X_{1} \cdot X_{2}+0.124 \cdot X_{2} \cdot X_{3}$ & 0.959 & 0.919 & 24.5 & 2.59 \\
\hline$Y_{3}=21.789-1.264 \cdot X_{1}-1.243 \cdot X_{2}+0.041 \cdot X_{1} \cdot X_{2}$ & 0.855 & 0.742 & 7.10 & 2.66 \\
\hline
\end{tabular}

(*) Statistically significant for $\mathrm{p}<0.05$.

(a)

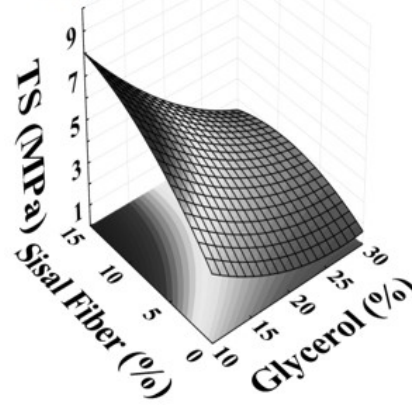

(d)
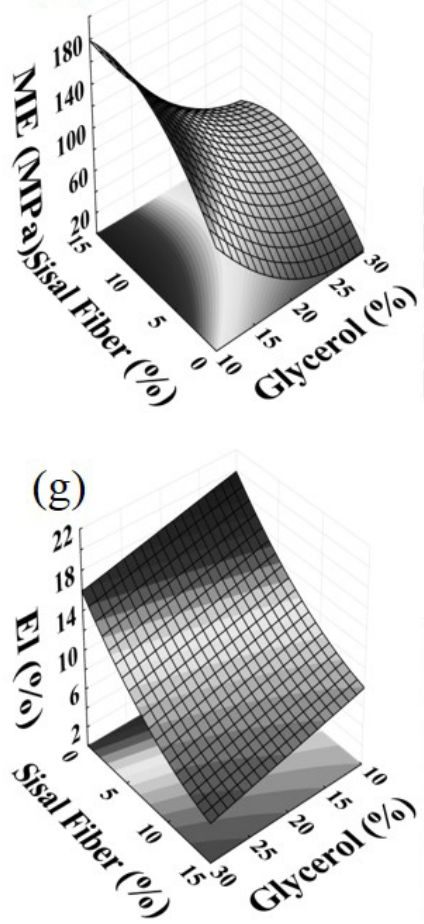

(b)

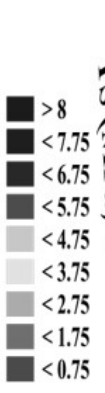

(e)

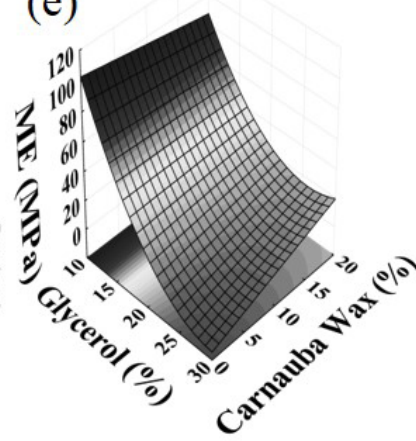

(h)
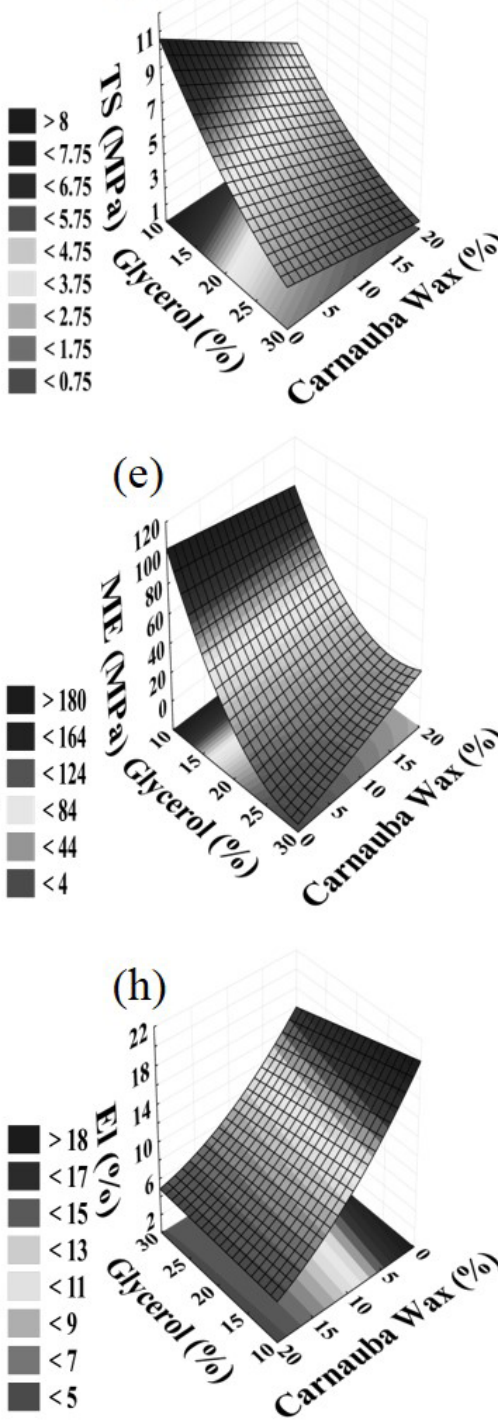

(c)

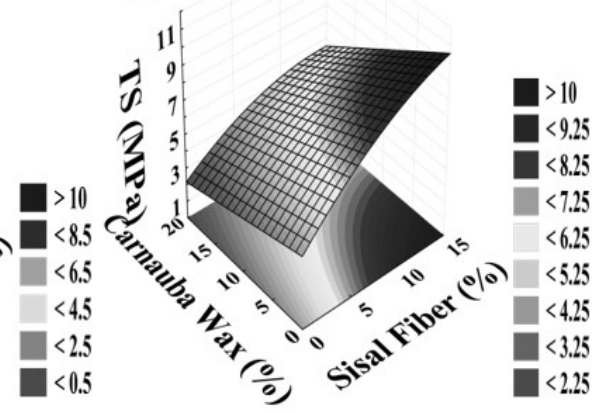

(f)

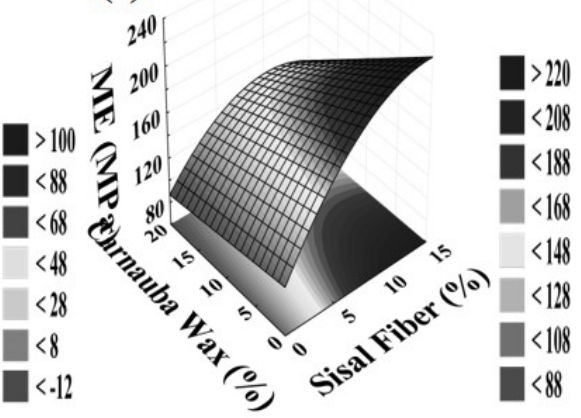

(i)

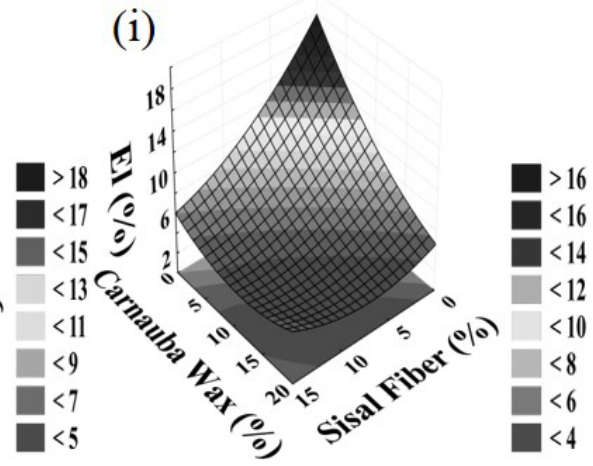

Figure 3. Response surfaces for tensile strength (TS), modulus of elasticity (ME) and elongation at rupture (El) of the biocomposites as a function of: concentration of glycerol and sisal fiber with carnauba wax fixed at $(\mathrm{a}-10 \% \mathrm{CW}),(\mathrm{d}-10 \% \mathrm{CW})$ and $(\mathrm{g}-0 \% \mathrm{CW})$; concentration of glycerol and carnauba wax with sisal fiber fixed at $(\mathrm{b}-15 \% \mathrm{SF}),(\mathrm{e}-0 \% \mathrm{SF})$ and $(\mathrm{h}-0 \% \mathrm{SF})$; concentration of sisal fiber and carnauba wax with glycerol fixed at $(c-10 \% \mathrm{G}),(\mathrm{f}-10 \% \mathrm{G})$ and $(\mathrm{i}-20 \% \mathrm{G})$.

agglomerations and an insufficiency of matrix to cover the fibers ${ }^{[3,7,25]}$.

The addition of carnauba wax associated with an increase of SF content causes a reduction in TS and ME, as shown in Figure 3 (c) and (f) and by the negative linear parameter of the interaction between these two factors. Carnauba wax is hydrophobic and does not show good interaction with the fibers and starch matrix ${ }^{[13,19]}$. A higher $\mathrm{CW}$ content 
increases the number of wax particles located at the fibermatrix interface, reducing interfacial adhesion and stress transfer between them.

The fitted models express the fact that a rise in $\mathrm{G}$ content cause a decrease in the TS and ME values, as shown in Figure 3 (b) and (e). Actually, glycerol interacts with the cassava starch matrix through hydrogen bonds, increasing the spaces and mobility between the polymer chains and reducing the matrix crystallinity. This makes the material more flexible and less resistant ${ }^{[6,20,26]}$.

With respect to the elongation at break (El), as can be seen in Figure $3(\mathrm{~g})$ to (i) and through the negative linear coefficients for SF and CW contents, the increase of both factors causes a reduction in stretching. The reduction due to the addition of the SF can be explained by the increase in the crystallinity of the material, reducing the mobility between the polymer chains and the flexibility, as observed by authors who added lignocellulosic fibers in starch matrices ${ }^{[3,7]}$. The reduction in the elongation at break by the addition of carnauba wax is possibly due to its anti-plasticizing effect, especially in high concentrations ${ }^{[6,20]}$.

\section{Conclusions}

From the obtained results, it can be concluded that the high concentration of carnauba wax leads to the formation of voids and agglomerates of this component due to its inability to mix with the matrix. The carnauba wax is distributed throughout the matrix and also between the fiber and the matrix reducing the fiber-matrix interfacial adhesion, which compromises the mechanical properties, decreasing the resistance of the biocomposites. An increase in the percentage of sisal fiber and carnauba wax provides an increase in the crystallinity of the biocomposite, while increasing the percentage of glycerol reduces crystallinity. All fitted models were significant and the addition of sisal fiber significantly increased TS and ME, whereas carnauba wax and glycerol had an opposite effect. The sisal fiber remained adhered to the matrix after the tensile test, which revealed good adhesion to the cassava starch matrix, while the carnauba wax biocomposite showed the formation of agglomerates of this component and the presence of voids, revealing that it does not have a good interaction with the matrix. According to the model obtained the maximum values of TS and ME would be obtained with the concentrations of $20.72 \%$ and $31.94 \%$ of sisal fiber, respectively. Finally, a biocomposite with $7.5 \%$ sisal fiber, $10 \%$ carnauba wax and $10 \%$ glycerol would be useful as biodegradable material, since it presented a good structure, without sisal fiber or carnauba wax release, as well as suitable mechanical properties.

\section{Acknowledgment}

Acknowledgment to UFERSA and CAPES.

\section{References}

1. Dicker MPM, Duckworth PF, Baker AB, Francois G, Hazzard MK, Weaver PM. Green composites: A review of material attributes and complementary applications. Composites Part A: Applied Science and Manufacturing. 2014;56:280-289.

2. Gurunathan T, Mohanty S, Nayak SK. A Review of the Recent Developments in Biocomposites Based on Natural Fibres and Their Application Perspectives. Composites Part A: Applied Science and Manufacturing. 2015;77:1-25.

3. Ramírez MGL, Satyanarayana KG, Iwakiri S, Muniz GB, Tanobe V, Flores-Sahagun TS. Study of the properties of biocomposites. Part I. Cassava starch-green coir fibers from Brazil. Carbohydrate Polymers. 2011;86(4):1712-1722.

4. Ramírez MGL, Satyanarayana KG, Manríquez-González R, Iwakiri S, Muniz GB, Flores-Sahagun TS. Bio-composites of cassava starch-green coconut fiber: Part II - Structure and properties. Carbohydrate Polymers. 2014;102:576-583.

5. Lara SC, Salcedo F. Gelatinization and retrogradation phenomena in starch/montmorillonite nanocomposites plasticized with different glycerol/water ratios. Carbohydrate Polymers. 2016;151:206-212.

6. Muscat D, Tobin MJ, Guo Q, Adhikari B. Understanding the distribution of natural wax in starch-wax films using synchrotron-based FTIR (S-FTIR). Carbohydrate Polymers. 2014;102:125-135.

7. Saleh MA, Haron MHA, Saleh AA, Farag M. Fatigue behavior and life prediction of biodegradable composites of starch reinforced with date palm fibers. International Journal of Fatigue. 2017;103:216-222.

8. Liang J, Ludescher RD. Effects of glycerol on the molecular mobility and hydrogen bond network in starch matrix. Carbohydrate Polymers. 2015;115:401-407.

9. Balakrishnan P, Sreekala MS, Kunaver M, Huskić M, Thomas S. Morphology, transport characteristics and viscoelastic polymer chain confinement in nanocomposites based on thermoplastic potato starch and cellulose nanofibers from pineapple leaf. Carbohydrate Polymers. 2017;169:176-188.

10. Narkchamnan S, Sakdaronnarong C. Thermo-molded biocomposite from cassava starch, natural fibers and lignin associated by laccasemediator system. Carbohydrate Polymers. 2013;96(1):109-117.

11. Belaadi A, Bezazi A, Bourchak M, Scarpa F, Zhu C. Thermochemical and statistical mechanical properties of natural sisal fibres. Composites Part B: Engineering. 2014;67:481-489.

12. Jawaid M, Sapuan SM, Alothman OY. Green Biocomposites: Manufacturing and Properties. Cham, Switzerland: Springer International Publishing; 2017.

13. Rodrigues DC, Caceres CA, Ribeiro HL, Abreu RFA, Cunha AP, Azeredo HMC. Influence of cassava starch and carnauba wax on physical properties of cashew tree gum-based film. Food hydrocolloids. 2014;38:147-151.

14. Chiumarelli M, Hubinger MD. Evaluation of edible films and coatings formulated with cassava starch, glycerol, carnauba wax and stearic acid. Food hydrocolloids. 2014;38:20-27. 
15. American Society for Testing Materials (ASTM). D3039/ D3039M-14 - Standard Test Method for Tensile Properties of Polymer Matrix Composite Materials. West Conshohocken, PA: ASTM International; 2014.

16. American Society for Testing Materials (ASTM). E104-02 Standard Practice for Maintaining Constant Relative Humidity by Means of Aqueous Solutions. West Conshohocken, PA: ASTM International; 2012.

17. Jouki M, Khazaei N, Ghasemlou M, Hadinezhad M. Effect of glycerol concentration on edible film production from cress seed carbohydrate gum. Carbohydrate Polymers. 2013;96(1):39-46.

18. Esmaeili M, Pircheraghi G, Bagheri R. Optimizing mechanical and physical properties of thermoplastic starch via tuning the molecular microstructure through co-plasticization by sorbitol and glycerol. Polymer International. 2017;66(6):809-819.

19. Mehyar GF, Al-Ismail K, Han JH, Chee GW. Characterization of Edible Coatings Consisting of Pea Starch, Whey Protein Isolate, and Carnauba Wax and their Effects on Oil Rancidity and Sensory Properties of Walnuts and Pine Nuts. Journal of Food Science. 2012;77(2):E52-59.

20. Chiumarelli M, Hubinger MD. Stability, solubility, mechanical and barrier properties of cassava starch - Carnauba wax edible coatings to preserve fresh-cut apples. Food Hydrocolloids. 2012;28(1):59-67.
21. Ibrahim H, Farag M, Megahed H, Mehanny S. Characteristics of starch-based biodegradable composites reinforced with date palm and flax fibers. Carbohydrate Polymers. 2014;101:11-19.

22. Villalobos-Hernández JR, Müller-Goymann CC. Sun protection enhancement of titanium dioxide crystals by the use of carnauba wax nanoparticles: The synergistic interaction between organic and inorganic sunscreens at nanoscale. International Journal of Pharmaceutics. 2006;322(1-2):161-170.

23. Zainuddin SYZ, Ahmad I, Kargarzadeh H, Abdullah I, Dufresne A. Potential of using multiscale kenaf fibers as reinforcing filler in cassava starch-kenaf biocomposites. Carbohydrate Polymers. 2013;92(2):2299-2305.

24. Prachayawarakorn J, Chaiwatyothin S, Mueangta S, Hanchana A. Effect of jute and kapok fibers on properties of thermoplastic cassava starch composites. Materials and Design. 2013;47:309-315.

25. López JP, Mutjé P, Carvalho A, Curvelo AAS, Gironès J. Newspaper fiber-reinforced thermoplastic starch biocomposites obtained by melt processing: Evaluation of the mechanical, thermal and water sorption properties. Industrial Crops \& Products. 2013;44:300-305.

26. Sanyang ML, Sapuan SL, Jawaid M, Ishak MR, Sahari J. Effect of Plasticizer Type and Concentration on Tensile, Thermal and Barrier Properties of Biodegradable Films Based on Sugar Palm (Arenga pinnata) Starch. Polymers. 2015;7(6):1106-1124. 